\title{
Pretreatment effect of gold/iron/zeolite-Y on carbon monoxide oxidation
}

\author{
Yih-Ming Kang, Ben-Zu Wan * \\ Department of Chemical Engineering, National Taiwan University, Taipei, Taiwan, Taiwan, ROC
}

\begin{abstract}
A gold/iron/zeolite- $Y$ catalyst was prepared by cation-exchange of iron-impregnated zeolite-Y with a chloroauric acid solution and subjected to various pretreatments prior to being used in carbon monoxide oxidation. The physical properties of the pretreated catalyst were characterized by X-ray powder diffraction, UV-Vis diffuse reflectance spectroscopy, temperature-programmed reduction and temperature-programmed desorption of carbon monoxide. By comparing to gold/zeolite-Y, the presence of iron oxide was found to hinder the sintering of gold metal during high-temperature treatment. The most active and water-durable catalyst was obtained by heating gold/iron/Y in a stream of humidified inert gas flow. The active sites on the catalyst were proposed to be gold hydroxide species surrounded by iron oxide.
\end{abstract}

Keywords: Gold; Iron oxide; Zeolite; Pretreatment; Water; Carbon monoxide oxidation

\section{Introduction}

The use of catalysts for carbon monoxide oxidation around room temperature is an important subject in a large number of industrial processes, in environmental protection and in special apparatus $[1-4]$. For instance, because the separation of carbon dioxide from a mixture of gases (e.g. also containing nitrogen, oxygen or methane) is usually much easier than that of carbon monoxide, the removal of carbon monoxide through oxidation to carbon dioxide is required in many industrial processes. On the other hand, it was reported that the amount of $\mathrm{CO}$ emitted into the atmosphere was the greatest among all of the air pollutants, or even to exceed the sum of all the other air pollutants [5]. Hence, carbon monoxide oxidation is

\footnotetext{
* Corresponding author.
}

one of the most important reactions in environmental protection. In the case of a $\mathrm{CO}_{2}$ laser, the re-combination of $\mathrm{CO}$ and $\mathrm{O}_{2}$ formed by dissociation of $\mathrm{CO}_{2}$ during discharge is essential to sustain the efficiency of laser performance, because the presence of $\mathrm{O}_{2}$ can cause a breakdown of the electrical field in the laser cavity.

Up to now, Hopcalite catalyst (mainly composed of $\mathrm{Mn}$ and $\mathrm{Cu}$ mixed oxides) has been the most important commercialized catalyst for $\mathrm{CO}$ oxidation. However, its water-durability is poor and it is not active around ambient temperature [6]. Recently, Haruta et al. [7,8] reported that gold catalysts prepared by coprecipitation method were active for carbon monoxide oxidation even at a temperature as low as $-70^{\circ} \mathrm{C}$. However, by such a coprecipitation method, the surface areas of catalysts were low and the gold loadings were usually larger than $10 \mathrm{wt} .-\%$. As a result, a signif- 
icant amount of gold probably buried inside the host metal oxide particles and could not be used for CO oxidation. Since gold is a noble metal, it is important to reduce the gold loading and to increase gold dispersion in the catalysts before they can be commercialized.

In our previous work, supported gold catalysts were prepared by cation-exchange of gold ions into varied exchangeable supports, e.g. zeolite $Y$, iron-impregnated zeolite $\mathrm{Y}$, etc. [9-11]. The preparation procedures were generally as follows: a support was added into a stirring solution of chloroauric acid, then the solution was heated and maintained at $80^{\circ} \mathrm{C}$ for $16 \mathrm{~h}$. After filtration, washing and drying, the exchanged gold catalysts were obtained. The as-prepared gold/zeolite-Y was found to be highly active without any pretreatment, but it irreversibly deactivated during the reaction tests or after thermal treatment. The deactivation was mainly attributed to the transformation of gold ions into gold metal of poor activity. In contrast to gold/zeolite-Y, gold/iron/zeolite$Y$ possessed high activity even after reduction at high temperatures. This was ascribed to the fact that the reduced gold/iron/zeolite-Y catalyst can catch and release oxygen at low temperature. Hsiao [12] used silica alumina as the support for cation-exchange gold ions and concluded that the $\mathrm{pH}$ of the filtrate determined the activities as well as the gold loadings of the as-prepared gold catalysts. Under the same gaseous flow rates as those in the work of Haruta et al. [8], some of the asprepared gold catalysts in Hsiao's work could possess $100 \% \mathrm{CO}$ conversion at $0^{\circ} \mathrm{C}$, although the amount of gold used was only about one twentieth of that used in ref. [8].

In the present study, the pretreatment effect of gold/iron/zeolite-Y on carbon monoxide oxidation, either in the presence or absence of water vapour, were investigated. Characterization techniques used were $X$-ray powder diffraction (XRD), UV-Vis diffuse reflectance spectroscopy, temperature-programmed reduction (TPR) and temperature-programmed desorption of carbon monoxide (TPD of CO). The aim of this study is to rationalize the catalytic activity of gold/iron/
zeolite-Y in $\mathrm{CO}$ oxidation after pretreatment under various conditions.

\section{Experimental}

\subsection{Catalysts}

In the present study, a gold/iron/zeolite-Y catalyst was prepared first by incipient-wetness impregnation of zeolite-Y $(\mathrm{Si} / \mathrm{Al}=2.28$, Conteka) with iron(III) nitrate solution. After calcination, the resultant sample termed $\mathrm{Fe} / \mathrm{Y}$ was added into a chloroauric acid $\left(\mathrm{HAuCl}_{4} \cdot 3 \mathrm{H}_{2} \mathrm{O}\right.$, Merck) solution under stirring, and then the solution was heated and maintained at $80^{\circ} \mathrm{C}$ for $16 \mathrm{~h}$. The solid was filtered, washed and dried at $60^{\circ} \mathrm{C}$ for $6 \mathrm{~h}$ in air. The resultant catalyst was termed $\mathrm{Au} / \mathrm{Fe} / \mathrm{Y}$. The gold and iron contents were 3.6 and 4.9 wt.-\%, respectively. A reference sample was prepared by incipient-wetness impregnation of zeolite-Y with an aqueous solution of chloroauric acid, and then dried under the same conditions as above. This reference sample, termed as $\mathrm{HAuCl}_{4} / \mathrm{Y}$, contained 0.94 wt.-\% of Au.

\subsection{Characterization}

The X-ray diffraction studies were performed by using a MAC Science diffractometer (model MXP-3) with $\mathrm{Cu} \mathrm{K} \alpha$ radiation at $40 \mathrm{kV}$ and 30 $\mathrm{mA}$. The patterns were obtained by the fixed-time method, namely, the scanning was held for $5 \mathrm{sec}$ ond over $0.02^{\circ}$ of $2 \Theta$ intervals. The forms of gold or iron species over as-prepared or pretreated $\mathrm{Au}$ / $\mathrm{Fe} / \mathrm{Y}$ were identified by comparing with the JCPDS powder diffraction file. The experimental procedures and the apparatus for TPR were described in detail in ref. [13]. TPD of CO was carried out in the same apparatus as TPR except that the trap used for condensing water vapor in TPR was removed. After being pretreated under the desired conditions, the sample was exposed in a stream of $\mathrm{CO} / \mathrm{He}$ gas mixture $(6 \mathrm{ml} / \mathrm{min}$ of $\mathrm{CO}$ and $30 \mathrm{ml} / \mathrm{min}$ of $\mathrm{He}$ ) at $40^{\circ} \mathrm{C}$ for $1 \mathrm{~h}$, and then cooled to room temperature. The TPD profile was 
Table 1

Various pretreatment procedures and their designations

Designation Pretreatment procedures

$\begin{array}{ll}\text { NP } & \text { Not pretreated } \\ \mathrm{O} & \text { Calcined in a stream of air }(32.67 \mathrm{ml} / \mathrm{min}) \text { at } 400^{\circ} \mathrm{C} \text { for } 2 \mathrm{~h} \\ \mathrm{R} & \text { Reduced in a stream of } \mathrm{H}_{2} / \mathrm{N}_{2}(30 \mathrm{ml} / \mathrm{min}, \mathrm{v} / \mathrm{v}=1 / 9) \text { at } 570^{\circ} \mathrm{C} \text { for } 2 \mathrm{~h} \\ \mathrm{~T} & \text { Thermal treated in a stream of } \mathrm{He}(30 \mathrm{ml} / \mathrm{min}) \text { at } 570^{\circ} \mathrm{C} \text { for } 2 \mathrm{~h} \\ \text { W } & \text { Treated in a stream of } \mathrm{He}(30 \mathrm{ml} / \mathrm{min}) \text { containing } 3 \text { vol. }-\% \text { of water vapour at } 570^{\circ} \mathrm{C} \text { for } 2 \mathrm{~h} \text {, and then thermally treated in a } \\ & \text { stream of } \mathrm{He}(30 \mathrm{ml} / \mathrm{min}) \text { at } 400^{\circ} \mathrm{C} \text { for } 1 / 2 \mathrm{~h}\end{array}$

obtained by heating the sample at a rate of $10^{\circ} \mathrm{C} /$ min from $30^{\circ} \mathrm{C}$ to $800^{\circ} \mathrm{C}$ under a $30 \mathrm{ml} / \mathrm{min}$ helium flow. For each TPR or TPD experiment, $0.056 \mathrm{~g}$ of $\mathrm{Au} / \mathrm{Fe} / \mathrm{Y}$ was used. The UV-Vis reflectance spectrum was measured with a Hitachi U3410 spectrophotometer with zeolite-Y served as reference.

\subsection{Activity measurements}

The catalytic activity of $\mathrm{Au} / \mathrm{Fe} / \mathrm{Y}$ for carbon monoxide oxidation, either in the presence or absence of water vapour, was measured in a continuous flow fixed-bed, quartz-tubular reactor (9 $\mathrm{mm}$ O.D.) at $40^{\circ} \mathrm{C}$ under atmospheric pressure. Before the reaction, $0.1 \mathrm{~g}$ or $0.05 \mathrm{~g}$ of $\mathrm{Au} / \mathrm{Fe} / \mathrm{Y}$ was either pretreated under various conditions, or directly used without any pretreatment. Table 1 lists the various pretreatment procedures and their designations. For the sake of simplicity, these designations will be used hereafter to describe the pretreatment procedures. For instance, if $\mathrm{Au} / \mathrm{Fe} /$ $\mathrm{Y}$ was calcined at $400^{\circ} \mathrm{C}$ for $2 \mathrm{~h}$ and then reduced at $570^{\circ} \mathrm{C}$ for $2 \mathrm{~h}$ before the reaction test or characterization, it will be named as OR catalyst.

During the reaction test, $32.67 \mathrm{ml} / \mathrm{min}$ of air and $0.33 \mathrm{ml} / \mathrm{min}$ of carbon monoxide controlled by Brooks mass flow controllers were fed into the reactor. Water vapor was incorporated into the reactant mixture by bubbling the reactant gases through an evaporator. The concentration of water vapour was maintained at ca. $3 \%$ by controlling the temperature of the evaporator at $25^{\circ} \mathrm{C}$. The products were analyzed by a gas chromatograph (China Chromatograph, 8700T) with hydrogen as carrier gas. A $15 \mathrm{ft}$. Carboxen ${ }^{\mathrm{TM}} 1000$ (1/8 in.
O.D., stainless steel, Supelco) was used for the separation of $\mathrm{O}_{2}, \mathrm{~N}_{2}, \mathrm{CO}$ and $\mathrm{CO}_{2}$.

\section{Results}

\subsection{X-ray powder diffraction}

Fig. 1 shows the XRD patterns of as-prepared and pretreated $\mathrm{Au} / \mathrm{Fe} / \mathrm{Y}$. The as-prepared sample has a diffraction pattern similar to that of zeolite$\mathrm{Y}$, and no crystalline structures of iron(III) oxide or gold(III) species were detected. After $\mathrm{Au} / \mathrm{Fe} /$ $Y$ was pretreated under various conditions, some differences in diffractograms could be observed around $38.2^{\circ}$ and $44.4^{\circ}$ in $2 \Theta$. They were the characteristic diffraction lines of $\mathrm{Au}(111)$ and $\mathrm{Au}(200)$, respectively. The mean crystalline diameter of gold metal was determined by Scher-

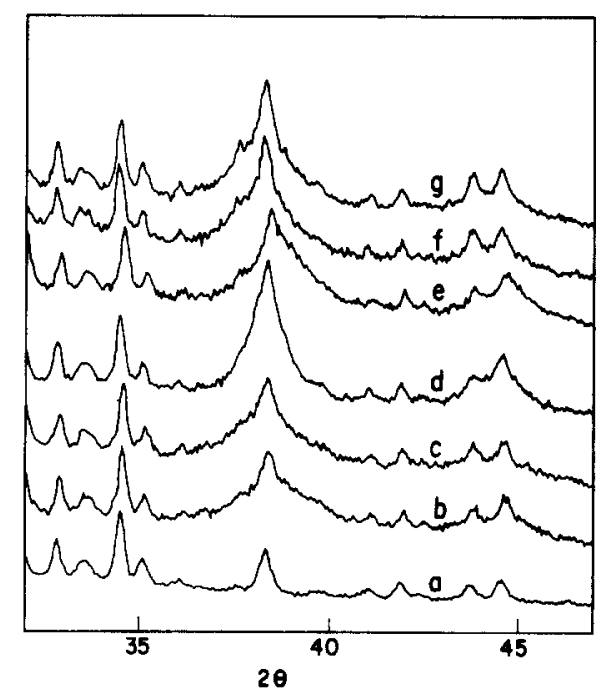

Fig. 1. The XRD patterns of as-prepared and pretreated $\mathrm{Au} / \mathrm{Fe} / \mathrm{Y}$. (a) NP, (b) R, (c) RO, (d) O, (e) OR, (f) T, (g) W. 
Table 2

Average diameters of gold metal on pretreated $\mathrm{Au} / \mathrm{Fe} / \mathrm{Y}$ or $\mathrm{Au} / \mathrm{Y}$

\begin{tabular}{llc}
\hline Catalyst & Pretreatment procedures & Au diameter $(\AA)$ \\
\hline $\mathrm{Au} / \mathrm{Fe} / \mathrm{Y}$ & W & 79 \\
& T & 79 \\
& OR & 68 \\
& O & 110 \\
& RO & 72 \\
& R & 47 \\
& NP & -
\end{tabular}

\begin{tabular}{clc}
$\mathrm{Au} / \mathrm{Y}$ & $\mathrm{OR}$ & 200 \\
& $\mathrm{O}$ & 200 \\
$\mathrm{NP}$ & - \\
\hline
\end{tabular}

rer equation according to the procedures described previously [10]. Table 2 lists the resultant particle diameters of gold metal on $\mathrm{Au} / \mathrm{Fe} / \mathrm{Y}$ after various pretreatment procedures. The $\mathrm{O}$ catalyst (calcination at $400^{\circ} \mathrm{C}$ ) has the largest average particle size of gold metal. However, the large gold metal particles seem to break into smaller particles, from 110 to $68 \AA$ in diameter, when the $\mathrm{O}$ catalyst was high-temperature reduced. Because gold metal particles on $\mathrm{Au} / \mathrm{Y}$, which was prepared by the same procedures as $\mathrm{Au} / \mathrm{Fe} / \mathrm{Y}$ except that the impregnation of iron oxide was omitted, could not redisperse after reduction as also shown in Table 2, the redispersion of gold metal might have something to do with the presence of iron oxide. Furthermore, the average particle sizes of gold metal on pretreated $\mathrm{Au} / \mathrm{Fe} / \mathrm{Y}$ were significantly smaller than those on $\mathrm{Au} / \mathrm{Y}$. These results suggest that there is probably a strong interaction between gold and iron oxide on $\mathrm{Au} / \mathrm{Fe} / \mathrm{Y}$, and iron oxide has the effect of hindering the sintering of gold metal as well as the redispersion of the sintered gold metal particles. On the other hand, the $\mathrm{R}$ catalyst possesses the best gold dispersion, while the average particle diameters of gold metal on the RO, OR, T and $\mathrm{W}$ catalysts were relatively larger and all in a close range.

\subsection{Temperature-programmed reduction}

The TPR results of $\mathrm{Fe} / \mathrm{Y}$ and as-prepared $\mathrm{Au} /$ $\mathrm{Fe} / \mathrm{Y}$ were shown in profiles (a) and (b) in
Fig. 2. As reported in our previous work [10], the peaks at 120 and $440^{\circ} \mathrm{C}$ of profile (b) correspond to the reduction of gold(III) species to gold metal and iron(III) oxide to iron(II) oxide, respectively. By calculating the area under profile (b), the peak at $150^{\circ} \mathrm{C}$ was suggested to be the reduction of iron oxide catalyzed by gold species [10]. The TPR results of $\mathrm{Au} / \mathrm{Fe} / \mathrm{Y}$ after varied pretreatment are shown in profiles (c)-(e) in Fig. 2 and profiles (a) - (c) in Fig. 3. Before the TPR tests, the $\mathrm{R}, \mathrm{OR}$ and $\mathrm{T}$ catalysts were exposed in air at $40^{\circ} \mathrm{C}$ for $24 \mathrm{~h}$. Among the six pretreated samples, the $\mathrm{R}$ catalyst possessed the lowest TPR peak which appears at $79^{\circ} \mathrm{C}$. That suggests that the reduced gold surface could chemisorb oxygen at $40^{\circ} \mathrm{C}$ and re-reduce at $79^{\circ} \mathrm{C}$. However, if the $R$ catalyst was exposed to a humidified air stream, the amount of chemisorbed oxygen decreased and the reduction temperature increased to $122^{\circ} \mathrm{C}$ (Fig. 3(d)). This suggests that water vapour is probably strongly adsorbed and suppresses the ability of $R$ catalyst to chemisorb oxygen. On the other hand, the peak intensity of the first reduction peak of profile (d) in Fig. 2 was larger than that of profile (e). In other words, the sites available for the chemisorption of oxygen on the $\mathrm{R}$ catalyst

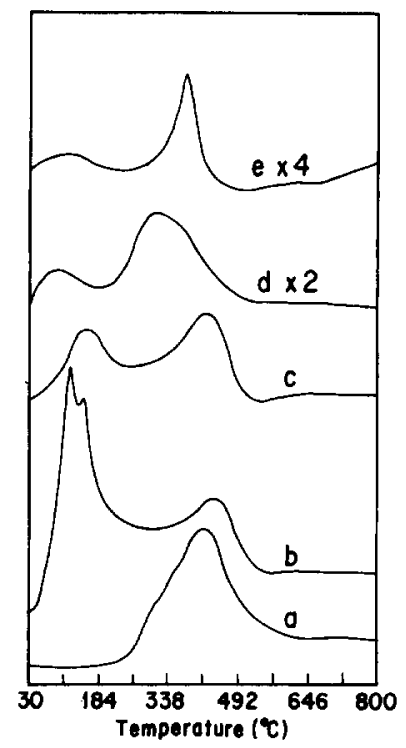

Fig. 2. TPR profiles of: (a) $\mathrm{Fe} / \mathrm{Y}$; (b) as-prepared $\mathrm{Au} / \mathrm{Fe} / \mathrm{Y}$, and pretreated $\mathrm{Au} / \mathrm{Fe} / \mathrm{Y}$; (c) $\mathrm{O}$; (d) $\mathrm{R}$ and then exposed in a stream of air at $40^{\circ} \mathrm{C}$ for $24 \mathrm{~h}$; (e) $O R$ and then exposed in a stream of air at $40^{\circ} \mathrm{C}$ for $24 \mathrm{~h}$. 


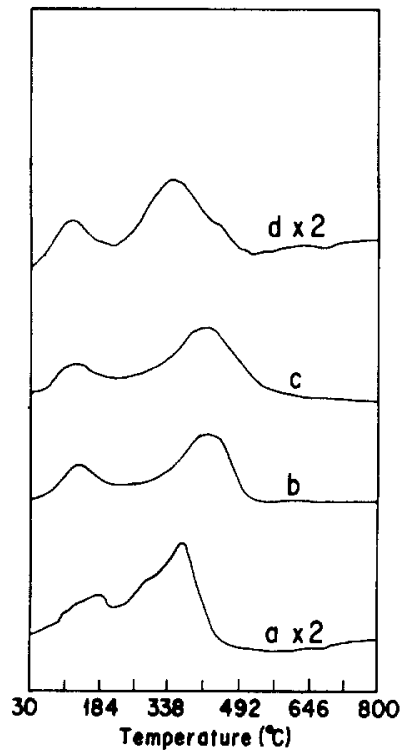

Fig. 3. TPR profiles of pretreated Au/Fe/Y: (a) RO, (b) $\mathrm{T}$ and then exposed in a stream of air at $40^{\circ} \mathrm{C}$ for $24 \mathrm{~h}$, (c) W, (d) R and then exposed in a stream of water/air $(3 / 97, v / v)$ at $40^{\circ} \mathrm{C}$ for $24 \mathrm{~h}$.

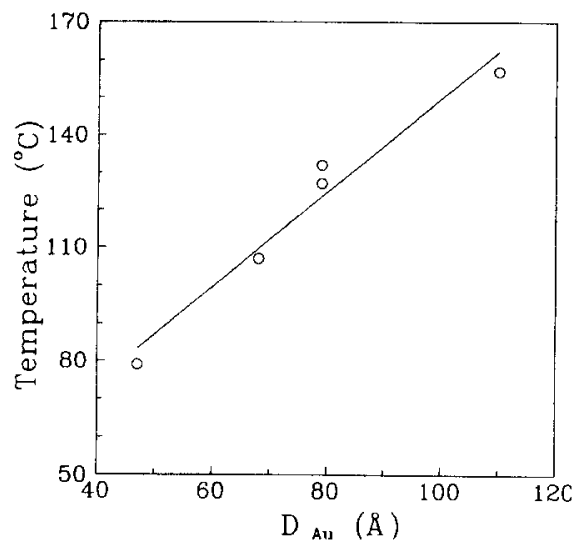

Fig. 4. A correlation between the temperatures of the first reduction peaks of pretreated $\mathrm{Au} / \mathrm{Fe} / \mathrm{Y}$ in TPR experiments and the average particle diameters of gold metals.

were more than those on the OR catalyst. It implies that the gold dispersion on the former is higher than that on the latter, which was consistent with the results of XRD.

It was found that the second reduction peaks of profiles (d) and (e) in Fig. 2 and profiles (a) and (d) in Fig. 3 were shift toward lower temperatures. This may be due to the redispersion of iron oxide which caused a decrease in the particle diameter of iron oxide. In addition, the fact that the reduced iron oxide may not be fully reoxidized and only the outer surface of it was oxidized may be also responsible for the shift in reduction temperature.

A linear relationship was found between the temperatures of the first reduction peaks of pretreated $\mathrm{Au} / \mathrm{Fe} / \mathrm{Y}$ and the mean particle diameters of gold metals on them, as shown in Fig. 4. The only exception was $\mathrm{RO}$ catalyst, which had the first reduction peak at $180^{\circ} \mathrm{C}$ and $72 \AA$ mean particle diameter of gold metal and possessed a point far away from the correlation line, probability due to the inhomogeneous particle distribution on zeolite-Y.

\subsection{TPD of carbon monoxide}

During the TPD measurement, the decomposition of gold or iron species and the degradation of zeolite-Y may occur and hence produce an extra profile which will append to the 'true' TPD profile of $\mathrm{CO}$, as shown in Fig. 5. It is noticed that the profile (c) became a horizontally straight line if a trap of $-85^{\circ} \mathrm{C}$ was positioned immediately after the TPD reactor. This indicates that during the

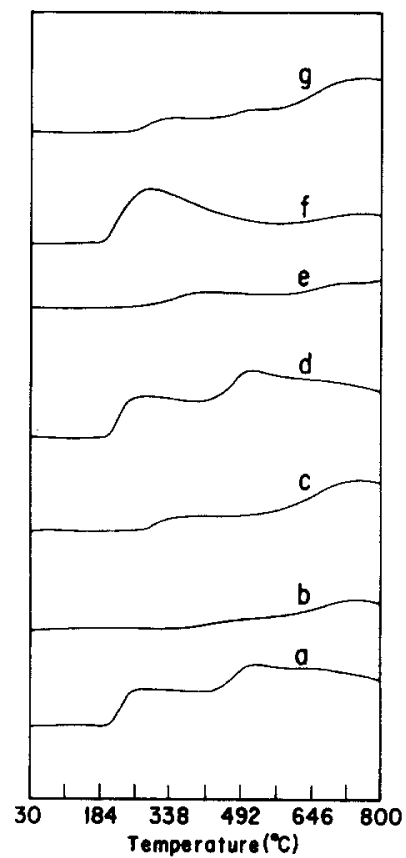

Fig. 5. TPD profiles of $\mathrm{Au} / \mathrm{Fe} / \mathrm{Y}$ after varied pretreatment: (a) $\mathrm{O}$, (b) R, (c) W, (d) O, (e) OR, (f) R, (g) W, where (d)-(g) samples were exposed in a stream of $\mathrm{CO} / \mathrm{He}(1 / 5, \mathrm{v} / \mathrm{v})$ at $40^{\circ} \mathrm{C}$ for $1 \mathrm{~h}$ before TPD measurement. 


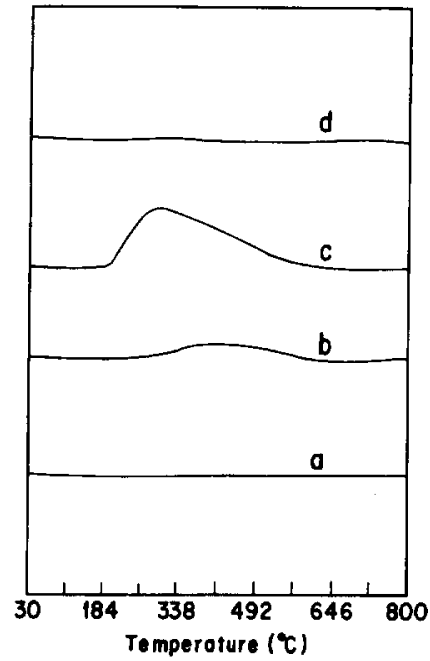

Fig. 6. The profiles of TPD of carbon monoxide of $\mathrm{Au} / \mathrm{Fe} / \mathrm{Y}$ after varied pretreatment: (a) $O$, (b) OR, (c) R, (d) W.

TPD measurement almost all of the desorbed species from the $\mathrm{W}$ catalyst were water. The TPD profiles of $\mathrm{CO}$, which were obtained by subtracting the decomposition or degradation profiles from the 'apparent' TPD profiles of $\mathrm{CO}$, of $\mathrm{Au}$ / $\mathrm{Fe} / \mathrm{Y}$ after varied pretreatment are shown in Fig. 6. For instance, profile (c) in Fig. 6 was obtained by subtracting profile (b) in Fig. 5 from profile (f) in the same figure. It can be observed that the amount of chemisorbed $\mathrm{CO}$ on the R catalyst was much more than those on the O, OR and $\mathrm{W}$ catalysts, and $\mathrm{CO}$ desorbed from $\mathrm{R}$ catalyst at a temperature higher than $190^{\circ} \mathrm{C}$. This suggests that carbon monoxide is more strongly adsorbed on the active sites of the $R$ catalyst than on those of the $O, O R$ and $W$ catalysts.

\subsection{UV-Vis diffuse reflectance spectra}

Fig. 7 shows the UV-Vis reflectance spectra of the investigated samples before pretreatment. The as-prepared impregnated $\mathrm{HAuCl}_{4} / \mathrm{Y}$ has two sharp absorption bands appeared around 226 and $318 \mathrm{~nm}$ (Fig. 7(a)), corresponding to the ligandto-metal charge transfer band and the $\mathrm{d}-\mathrm{d}$ transition band, respectively, of $\mathrm{AuCl}_{4}^{-}$[14]. The UV-Vis reflectance spectrum of $\mathrm{Fe} / \mathrm{Y}$ shows a broad band with the maximum at ca. $250 \mathrm{~nm}$. The spectrum has little changes after $\mathrm{Fe} / \mathrm{Y}$ being thermally treated under water vapour.

Fig. 8 shows the spectra of $\mathrm{Au} / \mathrm{Fe} / \mathrm{Y}$ after varied pretreatment. It was found that a new adsorption band appears around $550 \mathrm{~nm}$ after $\mathrm{Au} / \mathrm{Fe} / \mathrm{Y}$ being treated at high temperature. This absorption band is considered to have something to do with gold metal [15], and the appearance of gold metal on these pretreated samples was confirmed by the XRD results. In addition, it was found that the intensities of the shoulder around $340 \mathrm{~nm}$ on the $\mathrm{O}, \mathrm{T}$ and $\mathrm{W}$ catalysts were more pronounced than that on the as-prepared one. Because the major desorbed species from the $\mathrm{W}$ catalyst were water during the TPD measurement, the shoulder around $340 \mathrm{~nm}$ on the W catalyst was assigned to the existence of gold hydroxide. However, the 340 $\mathrm{nm}$ shoulder was also observed on the $\mathrm{O}$ and $\mathrm{T}$ catalysts which were obtained by treating the asprepared $\mathrm{Au} / \mathrm{Fe} / \mathrm{Y}$ in a dry gas (air or helium) stream. Therefore, the shoulder around $340 \mathrm{~nm}$ on the $O$ and $T$ catalysts were ascribed to the existence of gold oxides. When subjected to high temperature treatment in an inert gas, the gold oxide

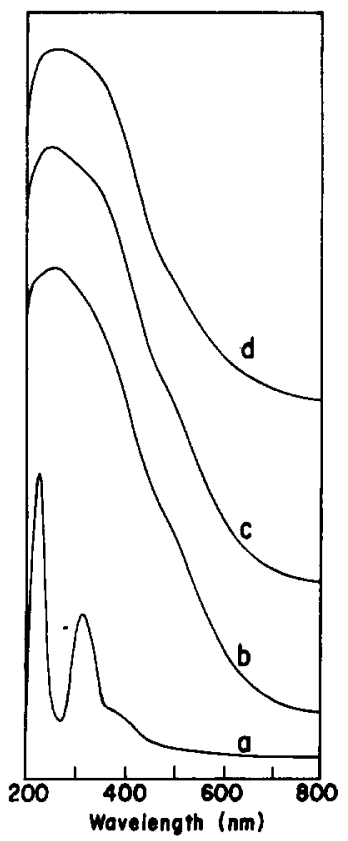

Fig. 7. UV-Vis reflectance spectra of (a) as-prepared $\mathrm{HAuCl}_{4} / \mathrm{Y}$, (b) $\mathrm{Fe} / \mathrm{Y}$, (c) $\mathrm{Fe} / \mathrm{Y}$ heated in a stream of water/helium $(3 / 97, \mathrm{v} /$ v) at $570^{\circ} \mathrm{C}$ for $2 \mathrm{~h}$, (d) as-prepared $\mathrm{Au} / \mathrm{Fe} / \mathrm{Y}$. 


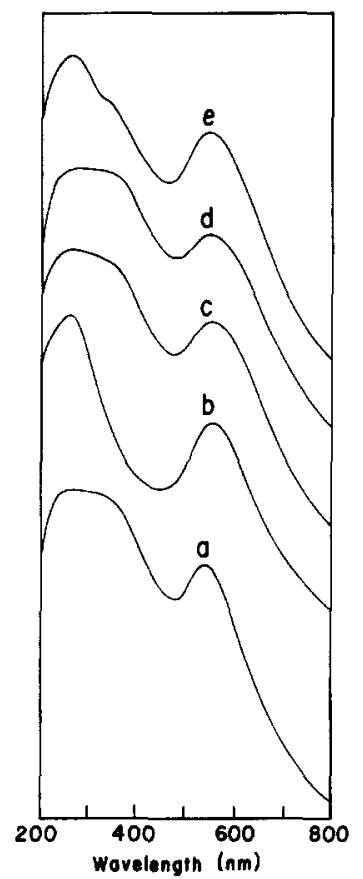

Fig. 8. UV-Vis reflectance spectra of $\mathrm{Au} / \mathrm{Fe} / \mathrm{Y}$ after varied pretreatment: (a) $\mathrm{O}$, (b) $\mathrm{R}$, (c) $\mathrm{T}$, (d) $\mathrm{W}$, (e) $\mathrm{W}$ and then heated in a stream of helium up to $800^{\circ} \mathrm{C}$.

or gold hydroxide may be dissociated to gold metal and oxygen or water. Therefore, it can be observed in Fig. 8(e) that the shoulder around $340 \mathrm{~nm}$ on the W catalyst decreased after the catalyst was treated to $800^{\circ} \mathrm{C}$ in a helium stream. Moreover, the shoulder around $340 \mathrm{~nm}$ of the $\mathrm{R}$ catalyst disappeared completely, due to the complete reduction to gold metal as shown in Fig. 8(b).

\subsection{Catalytic activities of pretreated $\mathrm{Au} / \mathrm{Fe} / \mathrm{Y}$}

The catalytic activities of $0.1 \mathrm{~g}$ of as-prepared or pretreated $\mathrm{Au} / \mathrm{Fe} / \mathrm{Y}$ in carbon monoxide oxidation in the absence of water vapour were examined at $40^{\circ} \mathrm{C}$, and the results are illustrated in Table 3 . It was observed that the $\mathrm{O}$ catalyst was inactive while the $\mathrm{OR}, \mathrm{T}$ and $\mathrm{W}$ catalysts were highly active. The conversion of carbon monoxide over the OR catalyst was retained at $100 \%$ for 5 $\mathrm{h}$, and then gradually decreased to $68 \%$ after $43 \mathrm{~h}$ on stream. The deactivation also occurred on other pretreated catalysts, but the activities were fully regenerated by a thermal treatment in an inert gas flow.

Although the R, OR and T catalysts were active for carbon monoxide oxidation in the absence of water vapour, they became nearly or essentially

Table 3

Catalytic activities of as-prepared or pretreated $\mathrm{Au} / \mathrm{Fe} / \mathrm{Y}$ for carbon monoxide oxidation ${ }^{\mathrm{a}}$

\begin{tabular}{lll}
\hline Pretreatment procedures & \multicolumn{2}{l}{ CO conversion (\%) } \\
\cline { 2 - 3 } & Initial & Latter (h on stream) \\
\hline NP & 10.3 & $11.1(4 \mathrm{~h})$ \\
O & 0.0 & $-(-)$ \\
R & 86.8 & $47.9(16 \mathrm{~h})$ \\
$\quad$ then T & 83.4 & $-(-)$ \\
OR & 100.0 & $67.7(43 \mathrm{~h})$ \\
RO & 33.3 & $24.5(63 \mathrm{~h})$ \\
T & 100.0 & $-(-)$ \\
W & 100.0 & $-(-)$ \\
\hline
\end{tabular}

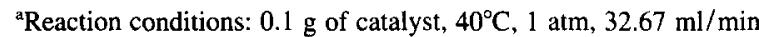
of air, and $0.33 \mathrm{ml} / \mathrm{min}$ of $\mathrm{CO}$.

Table 4

Effect of water vapour on the catalytic activities of pretreated $\mathrm{Au} /$ $\mathrm{Fe} / \mathrm{Y}^{\mathrm{a}}$

\begin{tabular}{|c|c|c|c|}
\hline \multirow[t]{2}{*}{ Pretreatment procedures } & \multirow[t]{2}{*}{ Reactants } & \multicolumn{2}{|c|}{ CO conversion $(\%)$} \\
\hline & & Initial & Latter (h) \\
\hline W & $\mathrm{CO} /$ air & 87 & - \\
\hline then & $\mathrm{CO} / \mathrm{air} / \mathrm{H}_{2} \mathrm{O}$ & 85 & $81(13 h)$ \\
\hline then & $\mathrm{CO} / \mathrm{air}$ & 74 & $65(5 h)$ \\
\hline then & $\mathrm{CO} / \mathrm{air} / \mathrm{H}_{2} \mathrm{O}$ & 66 & $78(2 h)$ \\
\hline then & $\mathrm{CO} / \mathrm{He} / \mathrm{H}_{2} \mathrm{O}$ & 0 & - \\
\hline OR & $\mathrm{CO} /$ air & 62 & - \\
\hline then & $\mathrm{CO} / \mathrm{air} / \mathrm{H}_{2} \mathrm{O}$ & 0 & $0(2 h)$ \\
\hline $\mathrm{OR}^{\mathrm{b}}$ & $\mathrm{CO} / \mathrm{air}$ & 18 & 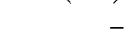 \\
\hline then & $\mathrm{CO} /$ air $/ \mathrm{H}_{2} \mathrm{O}$ & 0 & - \\
\hline $\mathrm{R}$ & $\mathrm{CO} /$ air & 49 & - \\
\hline then & $\mathrm{CO} / \mathrm{air} / \mathrm{H}_{2} \mathrm{O}$ & 0 & - \\
\hline $\mathrm{R}^{\mathrm{h}}$ & $\mathrm{CO} / \mathrm{air}$ & 21 & - \\
\hline then & $\mathrm{CO} / \mathrm{air} / \mathrm{H}_{2} \mathrm{O}$ & 0 & - \\
\hline RO & $\mathrm{CO} / \mathrm{air}$ & 11 & - \\
\hline then & $\mathrm{CO} / \mathrm{air} / \mathrm{H}_{2} \mathrm{O}$ & 0 & $0(2 \mathrm{~h})$ \\
\hline $\mathrm{T}$ & $\mathrm{CO} /$ air & 67 & - \\
\hline then & $\mathrm{CO} / \mathrm{air} / \mathrm{H}_{2} \mathrm{O}$ & 9 & - \\
\hline then $T$ & $\mathrm{CO} / \mathrm{air}$ & 71 & $48(3 h)$ \\
\hline
\end{tabular}

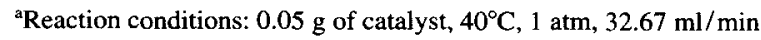
of air or helium, $0.33 \mathrm{ml} / \mathrm{min}$ of carbon monoxide; if used, water vapour concentration $=3$ vol. $\%$.

'The $\mathrm{OR}$ and $\mathrm{R}$ catalysts had been exposed in a stream of air at $40^{\circ} \mathrm{C}$ for $24 \mathrm{~h}$ prior to the reaction test. 
inactive when water vapour was incorporated into the reactant mixture, as shown in Table 4, where only $0.05 \mathrm{~g}$ of catalyst was used for each test run. Because the activities could be regained by a thermal treatment, the drastic decrease in activities was ascribed to the strong adsorption of water molecules on the active sites. In addition, it was found that if the $O R$ and $R$ catalysts were exposed in a strean of air at $40^{\circ} \mathrm{C}$ for $24 \mathrm{~h}$ prior to the reaction test, the produced catalysts possessed much lower activities than the OR and $R$ catalysts, and they were also not water-durable as the above three catalysts. In contrast to the activity drops on the R, OR, RO and T catalysts, the water durability of the $\mathrm{W}$ catalyst was very good. Furthermore, the reaction activity of the latter catalyst was better in the presence of water vapour than in a dry atmosphere run. Also shown in Table 4 was that watergas shift reaction over the $\mathrm{W}$ catalyst was absent since no $\mathrm{CO}$ conversion was detected when $\mathrm{He}$ instead of air was used in the reactant mixture.

\section{Discussion}

According to the Volcano Principle [16-18], metals or metal oxides will possess high catalytic activities in the oxidation of volatile organic compounds (VOCs) and carbon monoxide if they can catch and release oxygen at relatively low temperatures. In our previous work [10], the TPR tests were carried out on a series of catalysts $\mathrm{Au} /$ $\mathrm{Y}, \mathrm{Fe} / \mathrm{Y}$ and $\mathrm{Au} / \mathrm{Fe} / \mathrm{Y}$ which had been subjected to the $\mathrm{R}$ pretreatment procedures and then exposed in a stream of air at $40^{\circ} \mathrm{C}$ for $24 \mathrm{~h}$. The results showed that $\mathrm{Au} / \mathrm{Y}$ was easy to be reduced at low temperature, but the reduced $\mathrm{Au} / \mathrm{Y}$ could not be reoxidized in air at $40^{\circ} \mathrm{C}$. On the other hand, iron oxide on $\mathrm{Fe} / \mathrm{Y}$ was difficult to be reduced at temperatures lower than $300^{\circ} \mathrm{C}$, but the reduced iron oxide could be reoxidized at room temperature. These indicate that the bonding between goldoxygen was so weak that oxygen was easily dissociated from gold oxides. On the contrary, the bonding between iron-oxygen was too strong. In other words, either iron oxide or gold metal alone is not good catalyst to fulfill the oxidation-reduction cycle, and consequently the activities of $\mathrm{Fe} /$ $\mathrm{Y}$ and reduced $\mathrm{Au} / \mathrm{Y}$ were very poor in carbon monoxide oxidation. In contrast to $\mathrm{Au} / \mathrm{Y}$ and $\mathrm{Fe} /$ $\mathrm{Y}$, the reduced $\mathrm{Au} / \mathrm{Fe} / \mathrm{Y}$ could catch and release oxygen at low temperatures. Therefore, the reduced $\mathrm{Au} / \mathrm{Fe} / \mathrm{Y}$ could exhibit much higher activity than either $\mathrm{Fe} / \mathrm{Y}$ or reduced $\mathrm{Au} / \mathrm{Y}$.

In the present study, although the $\mathrm{R}$ catalyst could chemisorb oxygen at $40^{\circ} \mathrm{C}$ and release it at $79^{\circ} \mathrm{C}$ (the lowest temperature among catalysts of varied pretreatment), its activity was lower than the OR, T and $W$ catalysts. Therefore, the Volcano principle cannot be used alone to explain the present results on the activities of pretreated $\mathrm{Au} / \mathrm{Fe} /$ $Y$. In addition, the average particle diameter of gold metal on pretreated $\mathrm{Au} / \mathrm{Fe} / \mathrm{Y}$ was also not the unique determinant for the activity, although Haruta et al. [19] reported that the turnover frequencies for $\mathrm{CO}$ oxidation per surface gold atom increased with a decrease in the diameter of gold metal. The $\mathrm{R}$ catalyst which possessed the smallest gold metal particle size and the highest gold dispersion was not the most active catalyst.

Almost all of the loaded gold ions on the asprepared $\mathrm{Au} / \mathrm{Fe} / \mathrm{Y}$ were transformed into gold metal and migrated to the outer-surface of zeolite$\mathrm{Y}$ during high-temperature pretreatment as suggested by the results of XRD and ref. [10]. However, portions of gold ions, especially around iron oxide, were transformed into gold hydroxide, gold oxide or gold-iron mixed oxide according to the results of TPR, TPD and UV-Vis reflectance.

The state of gold sat near iron oxide is catalytically important because it is considered that carbon monoxide oxidation occurs at the interfacial perimeter of gold metal and iron oxide $[8,19,20]$. In other words, the gold species, either as gold metal, gold oxide, gold-iron oxide or gold hydroxide, around iron oxide are thought to be the active sites for carbon monoxide oxidation. However, it is difficult to differentiate gold oxide from gold-iron mixed oxide on pretreated $\mathrm{Au} / \mathrm{Fe} / \mathrm{Y}$ because the first reduction peaks of pretreated $\mathrm{Au}$ / Fe/Y in Fig. 2 and Fig. 3 were broad and both of the gold compounds gave rise to an absorption 
band around $340 \mathrm{~nm}$. For simplification, both of the gold compounds will be called 'gold oxides' hereafter. If we combined the results of TPR, TPD and UV-Vis reflectance, the state of gold around iron oxide on pretreated $\mathrm{Au} / \mathrm{Fe} / \mathrm{Y}$ can be known. When the $R$ and OR catalysts were exposed in air, gold metal around iron oxide could be oxidized to gold oxides. On the $\mathrm{O}$ and $\mathrm{RO}$ catalysts, most of gold near the interface of gold metal and iron oxide were gold oxides. On the W catalyst, gold hydroxide as well as gold metal and gold oxides existed at the perimeter of gold metal particle. In addition, it was noticed that the first reduction peak of the $\mathrm{T}$ catalyst was $182^{\circ} \mathrm{C}$ (not shown in the figures) instead of $132^{\circ} \mathrm{C}$ shown in Fig. 3(b), in which the profile was obtained by exposing the $\mathrm{T}$ catalyst to a stream of air at $40^{\circ} \mathrm{C}$ for $24 \mathrm{~h}$ prior to the TPR measurement. It was considered that the internal portion of the active particles on the $T$ catalyst right after high-temperature pretreatment was gold oxide which could be reduced at $182^{\circ} \mathrm{C}$, and the exterior surface of that was rich in gold metal which could be oxidized at $40^{\circ} \mathrm{C}$. The $132^{\circ} \mathrm{C}$ peak is attributed to the reduction of gold oxide on the exterior surface of the re-oxidized $\mathrm{T}$ catalyst. Therefore, in addition to gold oxides as suggested by the results of UV-Vis reflectance, some gold metal was probably also present around iron oxide on the surface of $T$ catalyst.

Since the activities of the $\mathrm{OR}$ and $\mathrm{R}$ catalysts evidently decreased if they were exposed in air prior to the reaction test (Table 4), gold oxides were considered to be less active than gold metal. This also accounts for that the activities of the RO and $O$ catalysts were lower than those of the $R$, $O R$ and $T$ catalysts. In fact, because the $O$ catalyst possessed the poorest gold dispersion and the least active sites, it was inactive during the reaction tests. Nevertheless, it was also noticed that the presence of gold oxides around the active sites could make catalyst water-durable, because the T catalyst did not become inactive in a humidified run. This suggests that the adsorption strength of water on the active sites aside gold oxides is weaker than that on plain gold metal surface. This is supported by the result of TPD in Fig. 6 that carbon monoxide (which is less polar than water) was adsorbed on the $O$ catalyst much weakly and in less amount than on the $\mathrm{R}$ and $\mathrm{OR}$ catalysts. In addition, because carbon monoxide oxidation was carried out under an oxidizing condition in this work, the active sites in gold metal form would be partially or gradually oxidized to gold oxides during the reaction test. Therefore, the decay in activity occurred over the R, OR, T and RO catalysts during a dry run could not be attributed only to the strong chemisorption of produced formate or carbonate as described in refs. [10,19,20]. The transformation of the active sites in gold metal form to gold oxides should be considered responsible for the deactivation.

Haruta et al. [19] reported that the superiority of their gold catalyst over Pt group catalysts was ascribed to the fact that $\mathrm{CO}$ adsorption on the former was reversible at room temperature and was much weaker than that on the latter. In the present study, because carbon monoxide is more strongly adsorbed on the $R$ catalyst than on the $O$, OR and W catalysts, it may block the active sites of the R catalyst and intensely compete with oxygen for the active sites. That was thought to be the reason that the $R$ catalyst was not the most active.

In contrast to the poor water-durability of the R, OR, RO, and T catalysts, the W catalyst was water-durable, and even the deactivated $\mathrm{W}$ catalyst, which was obtained when water vapour was not present in the reactant feed, could gradually recover its activity by incorporating water vapour into the reactant mixture. Based on the TPD results in Fig. 6, the amount and the strength of carbon monoxide adsorbed on the $\mathrm{R}$ or OR catalyst were more and stronger than those on the $\mathrm{W}$ catalyst. Because both of carbon monoxide and water are polar molecules, it is proposed that water may be also more strongly adsorbed on the active sites of the $R$ and $O R$ catalysts than on the $W$ catalyst. Hence, the $\mathrm{W}$ catalyst did not become inactive as water was present in the reactant mixture. In addition, because the catalytic behavior of the $\mathrm{W}$ catalyst was apparently different from those of the others, the active sites on the W catalyst was also considered to be not the same as those of the oth- 
ers. From the results of TPD and UV-Vis reflectance, hydroxyl groups coordinated to gold(III) ions were observed. Therefore, it is considered that gold hydroxide may play an important role in the activities of the $W$ catalyst.

Knell et al. [20] proposed a reaction sequence for $\mathrm{CO}$ oxidation over $\mathrm{Au} / \mathrm{ZrO}_{2}$. They reported that $\mathrm{CO}_{2}$ is desorbed from surface carbonate which is produced by oxidizing formate with surface oxygen, and formate is formed by insertion of $\mathrm{CO}$ into a surface hydroxyl group. In addition, they ascribed the deactivation of $\mathrm{Au} / \mathrm{ZrO}_{2}$ to the high concentration of surface formate which is very stable in the presence of excess oxygen and consequently blocks the active sites. A similar mechanism is proposed for the oxidation of carbon monoxide over the $\mathrm{W}$ catalyst in the present study. When CO is admitted to an empty site of the W catalyst, formate is formed by inserting $\mathrm{CO}$ into the hydroxyl group of gold hydroxide, and then the formate is oxidized by the surface oxygen to yield carbonate. The surface oxygen is provided by the neighboring active sites of gold metal or gold oxides form. Finally, $\mathrm{CO}_{2}$ is desorbed from surface carbonate.

Because carbon monoxide did not strongly adsorb on the $W$ catalyst as suggested by the results of TPD, the deactivation of the $W$ catalyst occurred in the absence of water vapour was not considered to be the result from the same reason as that of Knell et al. [20]. In our previous work [9-11], the deactivation of as-prepared gold/Y was mainly attributed to the fact that gold(III) ions transformed into gold metal of poor activity during the reaction test. Recently, we found that the deactivated gold/Y could be partly regenerated by exposing it in a humidified gas flow. Therefore, the deactivation of the $\mathrm{W}$ catalyst in the absence of water vapour is also attributed to the transformation of active sites, namely, proceeds via the following proposed reaction:

The gold hydroxide in the left-hand side was more active than the gold oxide species in the right-hand side. This was supported by that the activity of the $\mathrm{W}$ catalyst was much higher than that of the RO catalyst. Although it is assumed that the rate of the above undesirable reaction is slow because formic acid was not observed in the outlet stream from the reactor in the present study, the amount of the gold oxide species would increase with the time-on-stream and consequently the $\mathrm{W}$ catalyst was gradually deactivated. As water was incorporated into the reactant mixture, the gold oxide species would react with water to regenerate gold hydroxide and consequently the activity of $\mathrm{W}$ catalyst was regained. This also explains that the $\mathrm{W}$ catalyst could sustain its highly initial activity for a long time while water was present in the reaction feed.

\section{Conclusions}

Because of the presence of iron oxide, the average particle diameter of gold metal on pretreated $\mathrm{Au} / \mathrm{Fe} / \mathrm{Y}$ was smaller than that on the pretreated $\mathrm{Au} / \mathrm{Y}$, and even the sintered gold metal particles on the $\mathrm{O}$ catalyst could be broken into smaller particles after high-temperature reduction. Although the $\mathrm{R}$ catalyst possessed the highest gold dispersion and the lowest oxygen-releasing temperature, its activity was not the best. This is ascribed to that the adsorption competition between carbon monoxide and oxygen on the active sites of the $R$ catalyst was more sever than that on the others. In addition, the R, OR and T catalysts, possessing high activity in dry atmosphere, became nearly or essentially inactive as water vapour was present in the reactant mixture. This was due to the strong adsorption of water on the active sites of the catalyst. In contrast to the activity drop of the R, OR, RO and T catalysts, the $\mathrm{W}$ catalyst was water-durable, and even the deactivation occurred in dry reactant mixture could be gradually regenerated by incorporation of water vapour into the reactant feed. The active sites of the W catalyst was considered to be mainly composed of gold hydroxide surrounded by iron oxide. 


\section{Acknowledgements}

The financial support from the National Science Council in Taiwan, ROC, under contract No. NSC 84-0406-E-002-009 is gratefully appreciated.

\section{References}

[1] J.H. Kolts, Eur. Pat. Appl. EP 306944 (1989).

[2] W.H. Affleck and T.P. Moser, US Patent 4868841 (1989).

[3] A. Collins, J.C. Frost and P.J. Price, US Patent 4914071 (1990).

[4] H. Falke and G. Strauss, US Patent 5112787 (1992).

[5] M.J. Suess, K. Grefen and D.W. Reinisch, Ambient Air Pollutants from Industrial Sources, Elsevier, Amsterdam (1985).

[6] M.I. Brittan, H. Bliss and C.A. Walker, AIChE J., 16 (1970) 305.

[7] M. Haruta and H. Sano, Jpn. Kokai Tokkyo Koho, Jpn. Patent 60238148 (1985).
[8] M. Haruta, N. Yamada, T. Kobayashi and S. Iijima, J. Catal., 115 (1989) 301-309.

[9] Y.-M. Kang and B.-Z. Wan, in Proceeding of the 11th ROC Symposium on Catalysis and Reaction Engineering, Taipei, Taiwan, 1993, p. 171.

[10] Y.-M. Kang and B.-Z. Wan, to be published.

[11] Y.-M. Kang and B.-Z. Wan, Appl. Catal., in press.

[12] C.-Y. Hsiao, M.S. Thesis, Department of Chemical Engineering, National Taiwan University (1994).

[13] Y.-M. Kang and B.-Z. Wan, Appl. Catal. A: General, 114 (1994) 35-49.

[14] A.K. Gangopadhayay and A. Chakravorty, J. Chem. Phys., 35 (1961) 2206.

[15] K. Torigoe and K. Esumi, Langmuir, 8 (1992) 59-63.

[16] Y. Morooka and A. Ozaki, J. Catal., 5 (1966) 116-124.

[17] Y. Morooka, Y. Morikawa and A. Ozaki, J. Catal,, 7 (1967) 23-32.

[18] G.C. Bond, Heterogeneous Catalysis: Principles and Applications, 2nd ed., Oxford University Press (1987).

[19] M. Haruta, S. Tsubota, T. Kobayashi, H. Kageyama, M.J. Genet and B. Delmon, J. Catal, 144 (1993) 175-192.

[20] A. Knell, P. Barnickel, A. Baiker and A. Wokaun, J. Catal, 137 (1992) 306-321. 